\title{
Pengaruh Green Marketing Mix Terhadap Minat Beli Konsumen Pada Produk The Body Shop Di Jakarta Barat
}

\author{
Fellycia Chandra dan Hetty Karunia Tunjungsari \\ Program Studi Manajemen Fakultas Ekonomi Universitas Tarumanagara, Jakarta \\ Email:fellyciac.em@stu.untar,ac,id
}

\begin{abstract}
This research was conducted with the aim to know whether there is influence of green marketing mix on purchase intention in The Body Shop product in west jakarta. The study population is Jakarta citizen who has been a consumer of The Body Shop. Sampling method was done by purposive sampling. Methods of data collection was done by spreading questionnaires to 107 respondents. All data analysis techniques use SPSS 21. The assumption test has shown that all data has escaped the assumption requirements. The result of hypothesis testing shows that green marketing mix influence to purchase intention at The Body Shop in West Jakarta.
\end{abstract}

Keywords: Green Marketing Mix, Green Product, Green Price, Green Place, Green Promotion, Purchase Intention

\begin{abstract}
Abstrak: Penelitian ini dilakukan dengan tujuan untuk mengetahui apakah terdapat pengaruh green marketing mix terhadap minat beli pada produk The Body Shop di Jakarta Barat. Populasi penelitian adalah warga Jakarta yang pernah menjadi konsumen The Body Shop. Metode pengambilan sampel dilakukan dengan purposive sampling. Metode pengumpulan data dilakukan dengan menyebar kuesioner kepada 107 responden. Semua teknik analisis data menggunakan SPSS 21. Uji asumsi telah menunjukkan bahwa seluruh data telah lolos dari persyaratan asumsi. Hasil pengujian hipotesis menunjukkan bahwa green marketing mix berpengaruh terhadap minat beli pada produk The Body Shop di Jakarta Barat.
\end{abstract}

Kata Kunci: Green Marketing Mix, Green Product, Green Price, Green Place, Green Promotion, Purchase Intention

\section{LATAR BELAKANG}

Bumi pada saat ini mengalami permasalahan global warming, dimana indonesia adalah salah satu negara yang terkena dampaknya. Timbulnya kerusakan lingkungan, bencana alam dan berbagai permasalahan membuat banyak perushaan memproduksi produk yang berbahan dasar ramah lingkungan dan bebas dari bahan kimia. The body shop merupakan salah satu perusahaan kosmetik yang menggunakan bahan bebas kimia, ramah lingkungan sebagai bahan dasar pembuatan produknya. The body shop memiliki 5 nilai yang membuatnya lebih unggul daripada perusahaan lain yaitu agains animal testing, support community fair trade, acive self esteem, defend human rights, dan protect our planet.

The body shop harus bisa meyakinkan konsumen terhadap produknya sehingga tidak akan menghambat minat beli konsumen . minat beli yang positif mendorong konsumen untuk 
melakukan pembelian sebaliknya minat beli yang negatif akan menghambat konsumen untuk tidak melakukan pembelian terhadap produknya.

Green product adalah produk ramah lingkungan yang bebas dari bahan kimia, terbuat dari bahan yang dapat didaur ulang dan dapat digunakan kembali baik sebagian atau secara keseluruhan. Green price mengacu pada harga yang ditentukan dalam kebijakan perusahaan berkaitan dengan produk yang lebih berkualitas untuk pertimbangan lingkungan yang ditetapkan oleh aturan dan instruksi perusahaan. Green place harus sesuai dengan citra yang diinginkan oleh perusahaan unutk memasarkan produknya dan harus memiliki perbedaan dengen para pesaingnya . Green Promotion mengacu pada bagaimana cara perusahaan untuk menyalurkan informasi tentang produknya melalui iklan, promosi penjualan, pemasaran secara langsung agar mudah di terima oleh konsumen

Dari data diatas maka peneliti akan menganalisis faktor yang mempengaruhi minat beli konsumen pada produk the body shop di Jakarta Barat melalui green product, green price, green place, dan green promotion.

\section{KAJIAN TEORI}

Menurut (Tseng dan Hung, 2013) green product adalah :"environmentally friendly products or environmentally awareness products, are referred to as products designed to lessen the consumption of natural resources required and minimize the adversely environmental impacts through the whole life-cycles of these goods."

Green price, menurut (Polonsky, 2011) harga adalah faktor penting dan penting dari bauran pemasaran hijau. Sebagian besar konsumen membayar harga yang lebih tinggi hanya jika mereka tahu nilai tambah produk tersebut.

Green place Menurut (Mahmoud, 2017) green place adalah tempat mewakili suatu lokasi dimana produk dapat dibeli. Distribusi produk harus dari saluran yang meyakinkan, jelas dan terpercaya..

Green promotion Menurut (Praharjo, 2013) green promotion adalah iklan dalam strategi pemasaran yang dikaitkan dengan isu dalam lingkungan agar konsumen bisa membedakannya dengan promosi produk lainnya.

Minat beli Menurut (David, 2009) pengertian minat beli adalah keinginan yang timbul dari konsumen untuk memiliki suatu produk karena akibat dari beberapa dorongan. Sedangkan menurut (Margaret, 2006) minat beli muncul karena beberapa keputusan pembelian: keputusan merek, keputusan kuantitas, keputusan waktu, dan keputusan waktu pembayaran. 
Kerangka pemikiran dalam penelitian ini seperti digambarkan dibawah ini

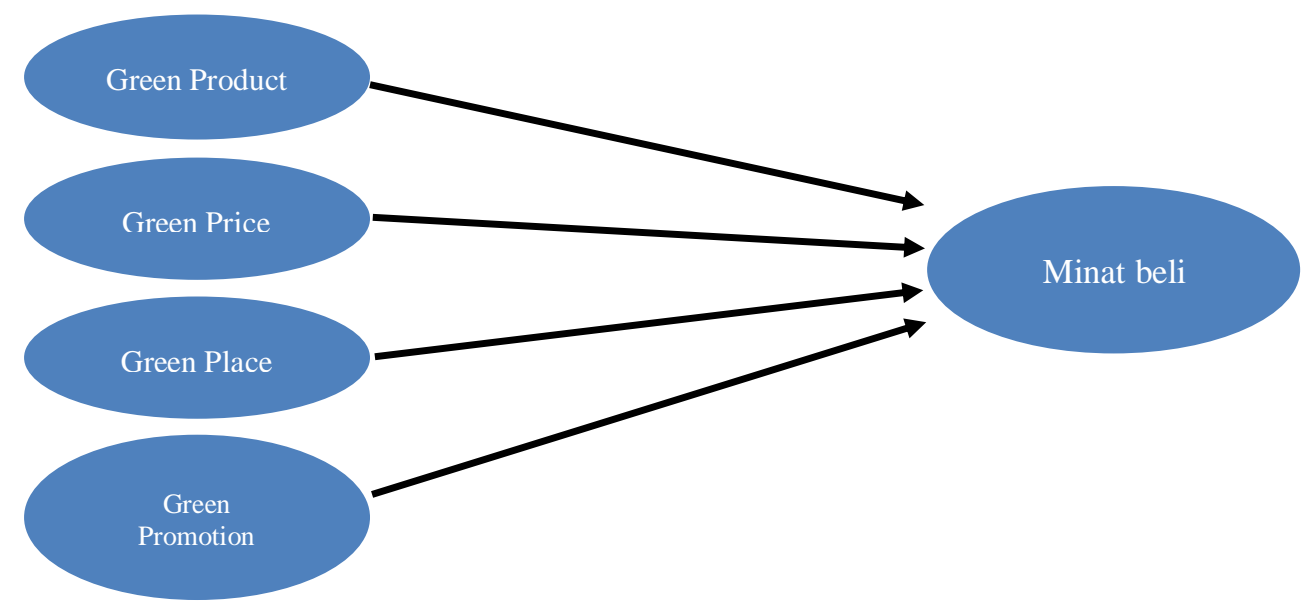

Gambar 1. Kerangka pemikiran

Hipotesis dari model yang dibangun di atas adalah sebagai berikut :

H1: Terdapat pengaruh green product terhadap minat beli pada produk The Body Shop di Jakarta.

H2: Terdapat pengaruh green price terhadap minat beli pada produk The Body Shop di Jakarta. H3: Terdapat pengaruh green place terhadap minat beli pada produk The Body Shop di Jakarta. H4: Terdapat pengaruh green promotion terhadap minat beli pada produk The Body Shop di Jakarta.

\section{METODOLOGI}

Objek penelitian ini difokuskan pada perusahaan The Body Shop yang berada di jakartqa barat. Pemilihan sampel dilakukan dengan cara purposive sampling method dengan kriteria-kriteria yang ditentukan dalam pengambilan sampel penelitian ini yaitu : Jenis kelamin, Usia, Pendidikan terakhir, Pekerjaan, Pendapatan / penghasilan per bulan, Pengeluaran per bulan . jumlah responden sebanyak 107 orang.

Variabel operasional dalam penelitian ini terdiri deari variabel independen ( green product, green price, green place dan green promotion ) dan variabel dependen ( minat beli ). Skala yang digunakan sebagai alat ukur dalam penelitian ini aalah skala Likert.

Dalam penelitian ini menggunakan Uji Statisik Deskriptif untuk menguji data sampel, kemudian menggunakan uji asumsi klasik yang terdiri dari Uji Normalitas, Uji Multikolinearitas dan Uji Heterokedastisitas. Sedangkan uji hipotesis menggunakan Uji f, Uji t dan Koefisien Deerminasi.

\section{HASIL UJI STATISTIK}

Uji statistik deskriptif yang menggambarkan tentang ringkasan data penelitian seperti mean, standar deviasi, minimum dan maksimum . Hasil statistik deskriptif green product memiliki nilai minimum sebesar 8 , nilai maksimum sebesar 20, nilai mean sebesar 16.85 , dan standar deviasi sebesar 1.946. hasil statistik deskripsi green price memiliki nilai minimum sebesar 7, nilai maximum sebesar 20, nilai mean sebesar 17.14 dan standar deviasi sebesar 2.333. hasil statistik deskripsi green place memilki nilai minimum sebesar 4, nilai maksimum 
20, nilai mean sebesar 16.54 dan standar deviasi sebesar 3,418. Hasil statistik deksripsi green promotion memiliki nilai minimum sebesar 9, nilai maximum sebesar 20, nilai mean sebesar 17.06, dan standar deviasi sebesar 2.273. hasil statistik deskripsi minat beli memiliki nilai minimum sebesar 8 , nilai maksimum sebesar 20, nilai mean sebesar 17.54 , dan standar deviasi sebesar 2.053 .

Uji Asumsi Klasik. Sebelum dilakukan pengujian hipotesis terlebih dahulu dilakukan uji asumsi klasik pada model regresi. Uji normalitas, penelitian ini menggunakan uji normalitas dengan One-sample Kolmogorov-Smirnov. Dalam penelitian ini menunjukkan nilai sig.(2tailed) sebesar $0.168>0.05$ berarti data berdistribusi normal dan model regresi memenuhi asumsi normalitas. Uji multikolinearitas, dilihat dari nilai tolarance atau VIF untuk menguji ada tidaknya multikolinearitas. Dari hasil pengolahan data diperoleh nilai tolerance $>0.10$ dan VIF $<10$ untuk semua variabel maka persamaan model regresi tidak mengandung multikolinearitas. Uji berikutnya adalah Uji Heterokedastisitas yang bertujuan untuk melihat ada tidaknya heteroskedastisitas dilihat dari nilai signifikansinya, di mana hasil pengolahan dalam penelitian ini menunjukkan nilai signifikasi > 0.05 untuk semua variabel maka persamaan model regresi tidak mengandung heterokedastisitas.

Berdasarkan hasil penelitian yang dilakukan, maka peneliti mencoba memberikan pokok-pokok temuan penelitian secara keseluruhan. Hasil Analisis regresi berganda, dapat disimpulkan persamaan model regresi yaitu:

$$
\begin{gathered}
\mathrm{Y}=1,716+0,244(\text { Green product })+0,233(\text { Green price })+0,104(\text { Green prlace }) \\
+0,352(\text { green promotion })+\mathrm{e}
\end{gathered}
$$

Dari persamaan diatas, nilai constant sebesar 1.716. hal ini menyatakan bahwa nilai variabel green product, green price, green place dan green promotion sama dengan nol atau diabaikan, maka minat beli nilainya tetap positif sebesar 1.716. nilai koefisien regresi variabel green product (X1) positif sebesar 0,244 maka setiap nilai green product bertambah akan meningkatkan nilai variabel minat beli sebesar 0,244 . nilai koefisien variabel green price (X2) positif sebesar 0,233 maka setiap nilai green price bertambah akan meningkatkan nilai variabel minat beli sebesar 0,233. nilai koefisien variabel green place (X3) positif sebesar 0,104 maka setiap nilai green place bertambah akan meningkatkan nilai variabel minat beli positif sebesar 0,104 . nilai koefisien variabel green promotion (X4) positif sebesar 0,352 maka setiap nilai green promotion bertambah akan meningkatkan nilai variabel minat beli sebesar 0,352.

Uji t (parsial) adalah uji yang digunakan untuk menguji keterkaitan secara individu antara variabel bebas dengan variabel terikat. Untuk menguji hipotesis nol ditolak atau diterima, titik tolaknya adalah bila nilai $\mathrm{p}$-value t-test $<$ atau $>0,05$, artinya jika nilai signifikansi dari variabel independen di bawah 0,05, maka H0 ditolak dan Ha diterima dan sebaliknya. 
Hasil uji ini dapat dilihat pada tabel dibawa ini:

Tabel 1. Koefisien Regresi

\begin{tabular}{|c|c|c|c|c|c|c|}
\hline \multirow{3}{*}{\multicolumn{2}{|c|}{ Model }} & \multicolumn{3}{|c|}{ Coefficients $^{a}$} & \multirow{3}{*}{$\mathrm{t}$} & \multirow{3}{*}{ Sig. } \\
\hline & & \multicolumn{2}{|c|}{$\begin{array}{l}\text { Unstandardized } \\
\text { Coefficients }\end{array}$} & \multirow{2}{*}{$\begin{array}{c}\text { Standardized } \\
\text { Coefficients } \\
\text { Beta }\end{array}$} & & \\
\hline & & $\mathrm{B}$ & Std. Error & & & \\
\hline \multirow{5}{*}{1} & (Constant) & 1,716 & 1,519 & & 1,130 & ,261 \\
\hline & Green Product & ,244 & ,087 & 231 & 2,802 & ,006 \\
\hline & Green Price & ,233 & ,065 & ,264 & 3,597 & ,000 \\
\hline & Green Place & ,104 & 041 & ,174 & 2,563 & ,012 \\
\hline & $\begin{array}{l}\text { Green Promotion } \\
\text { lent Variable: Minat }\end{array}$ & ,352 & ,074 & ,390 & 4,727 & ,000 \\
\hline
\end{tabular}

Untuk mengetahui korelasi variabel-variabel independen terhadap variabel dependen, maka dilakukan uji korelasi (R). Dalam penelitian ini menunjukkan nilai R sebesar 0.733 . Hal ini menunjukkan bahwa hubungan independen variabel dengan dependen variabel. Dan Uji Koefisien Determinasi ( R-Square)yang digunakan untuk mengetahui persentase sumbangan variabel bebas secara serentak terhadap variabel terikat menunjukkan angka 0.537 . Jadi, dapat disimpulkan bahwa 53,7\% varabel independen terhadap variabel dependen yang digunakan dalam model ini, sedangkan sisanya $46.3 \%$ diepengaruhi oleh faktor lain yang tidak ditetliti oleh peneliti.

\section{DISKUSI}

Hasil pengujian statistik menunjukkan bahwa variabel green product berpengaruh secara positif signifikan terhadap minat beli. Hasil variabel green price berpengaruh secara positif signifikan terhadap minat beli. Hasil variabel green place berpengaruh secara positif signifikan terhadap minat beli. Hasil pengujian variabel green promotion berpengaruh secara positif signifikan terhadap minat beli.

\section{PENUTUP}

Berdasarkan hasil pengujian data dalam penelitiaqn ini, Perusahaan The Body Shop yang ada di Jakarta Barat menunjukkan bahwa minat beli konsumen terhadap produk The Body Shop dipengaruhi oleh green product, green price, green place, dan green promotion.

Keterbatasan dari penelitian ini dikarenakan : peneliti hanya menggunakan perushaan The Body Shop yang ada di Jakarta Barat, penelitian ini hanya menggunakan pengguna/ responden yang menggunakan produk dari The Body Shop, peneliti hanya menggunakan empa variabel independen

Berdasarkan hasil dan keterbatasan di atas, maka saran yang apat diberikan untuk penelitian selanjutnya, yaitu menambah jumlah responden, memperluas wilayah yang lebih luas agar dapat menerangkan keadaan yang lebih objektif, memperluas variabel independen lainnya yang mempengaruhi minat beli. 


\section{DAFTAR PUSTAKA}

David, Fred R. (2009). Manajemen Strategis Konsep, Edisi 12. Jakarta: Salemba Empat.

Tseng SC and Hung SW (2013). A framework identifying the gaps between customers' expectations and their perceptions in green products. Journal of Cleaner Production, 59: 174-184.

Polonsky MJ (2011). Transformative green marketing: Impediments and opportunities. Journal of Business Research, 64(12): 1311-1319.

Praharjo, Ardik. (2013). Pengaruh Green Advertising terhadap Persepsi tentang Green Brand dan Jurnal Administrasi Bisnis (JAB). 